\title{
Reply to the letter by Huo et al. regarding our manuscript "The transition in the etiologies of hepatocellular carcinoma- complicated liver cirrhosis in a nationwide survey of Japan"
}

\author{
Hirayuki Enomoto $^{1} \cdot$ Shuhei Nishiguchi ${ }^{1,2}$
}

Received: 22 January 2021 / Accepted: 2 February 2021 / Published online: 11 March 2021

(C) Japanese Society of Gastroenterology 2021

We thank Huo et al. for their interest in our research [1]. In Japan, national measurements for anti-hepatitis viruses have been conducted with a large budget [2], and the causes of liver cirrhosis have remarkably changed over the past decade [3]. Our nationwide survey showed that a decrease in viral hepatitis-related HCC was responsible for the etiological changes in hepatocellular carcinoma (HCC)complicated liver cirrhosis in Japan [1]. As described in the discussion section of the paper [1], our survey focused on the etiological transition, and the collected data were limited to the number of cases per institution. Therefore, we cannot provide more detailed information, such as the stages of HCC or prognosis, of our cohort. However, better control of the hepatitis virus can reduce the risk of developing liver failure and allow cirrhotic patients to receive intensive treatment, suggesting that the prognosis of HCC patients has improved in Japan. As reported from Taiwan [4] and Italy [5], data concerning changes in the HCC stage and prognosis are clinically important and useful. We plan to collect data from participating institutions and analyze them in a future study. Thank you for your valuable comments.

Compliance with ethical standards

This comment refers to the article available online at https://doi.org/ $10.1007 / \mathrm{s} 00535-020-01748-\mathrm{x}$.

Hirayuki Enomoto

enomoto@hyo-med.ac.jp

1 Division of Gastroenterology and Hepatology, Department of Internal Medicine, Hyogo College of Medicine, Nishinomiya, Hyogo 663-8501, Japan

2 Department of Gastroenterology, Kano General Hospital, Osaka, Japan
Conflict of interest The authors declare that they have no conflicts of interest to disclose.

\section{References}

1. Enomoto H, Ueno Y, Hiasa Y, et al. The transition in the etiologies of hepatocellular carcinoma-complicated liver cirrhosis in a nationwide survey of Japan. J Gastroenterol. 2020. https://doi. org/10.1007/s00535-020-01748-x (Online ahead of print).

2. Tanaka J, Akita T, Ko K, Miura Y, et al. Countermeasures against viral hepatitis B and C in Japan: an epidemiological point of view. Hepatol Res. 2019;49:990-1002.

3. Enomoto H, Ueno Y, Hiasa Y, et al. Transition in the etiology of liver cirrhosis in Japan: a nationwide survey. J Gastroenterol. 2020;55:353-62.

4. Ho SY, Liu PH, Hsu CY, et al. Evolution of etiology, presentation, management and prognostic tool in hepatocellular carcinoma. Sci Rep. 2020;10:3925.

5. Garuti F, Neri A, Avanzato F, et al. The changing scenario of hepatocellular carcinoma in Italy: an update. Liver Int. 2020. https://doi.org/10.1111/liv.14735 (Online ahead of print).

Publisher's Note Springer Nature remains neutral with regard to jurisdictional claims in published maps and institutional affiliations. 